\title{
Comparison of Rates of Potentially Inappropriate Medication Use According to the Zhan Criteria for VA Versus Private Sector Medicare HMOs
}

\author{
MITCHELL J. BARNETT, PharmD, MS; PAUL J. PERRY, PhD; JODI D. LANGSTAFF, BA; and PETER J. KABOLI, MD, MS
}

\begin{abstract}
BACKGROUND: Inappropriate prescribing in the elderly is common, but rates across different health care systems and the impact of formulary restrictions are not well described.

OBJECTIVE: To determine if rates of inappropriate medication use in the elderly differ between the Veterans Affairs (VA) health care system and the private sector Medicare health maintenance organization (HMO) patients.

METHODS: A cross-sectional study design compared administrative pharmacy claims from 10 distinct geographic regions in the United States in the VA health care system and 10 analogous regions for patients enrolled in Medicare HMOs. The cohorts included 123,633 VA and 157,517 Medicare HMO patients aged 65 years and older. Inappropriate medication use was identified using the Zhan modification of the Beers criteria, which categorizes 33 potentially inappropriate drugs into 3 major classifications: "always avoid," "rarely appropriate," and "some indications." Comparisons between the VA health care system and the private sector Medicare HMO were performed for overall differences and stratified by gender and age. The drug formulary status of the Zhan-criteria drugs was known for the VA health system but not for the Medicare HMO patients.
\end{abstract}

RESULTS: Compared with private sector patients, VA patients were less likely to receive any inappropriate medication $(21 \%$ vs. $29 \%, P<0.001)$, and in each classification: always avoid ( $2 \%$ vs. $5 \%, P<0.001)$, rarely appropriate ( $8 \%$ vs. $13 \%$, $P<0.001$ ), and some indications ( $15 \%$ vs. $17 \%, P<0.001$ ). The rate of inappropriate drug use was lower in the VA compared with the private sector for males $(21 \%$ vs. $24 \%, P<0.001)$ and females ( $28 \%$ vs. $32 \%, P<0.001)$. Differences were consistent when stratified by age.

CONCLUSION: Compared with private sector Medicare HMOs, elderly VA patients were less likely to receive medications defined by the Zhan criteria as potentially inappropriate. A restrictive formulary that excludes 12 of the 33 Zhan criteria drugs may be a factor in the reduction of undesired prescribing patterns in elderly populations.

KEYWORDS: Health services research, Veterans Administration, Quality of care, Potentially inappropriate medications, Elderly, Drug contraindications

J Manag Care Pharm. 2006;12(5):362-70

\section{Authors}

MITCHELL J. BARNETT, PharmD, MS, is a health services research specialist, The Center for Research in the Implementation of Innovative Strategies in Practice (CRIISP), Iowa City VA Medical Center, Iowa City, Iowa, and an assistant professor, The Touro College of Pharmacy, Vallejo, California; PAUL J. PERRY, PhD, is a professor, The Touro College of Pharmacy, Vallejo, CA; JODI D. LANGSTAFF, BA, is a research assistant, CRIISP and a pharmacy student, University of Iowa, Iowa City; PETER J. KABOLI, MD, MS, is a senior scientist, CRIISP, and an assistant professor, Division of General Internal Medicine, Department of Internal Medicine, University of Iowa Carver College of Medicine, Iowa City.

AUTHOR CORRESPONDENCE: Mitchell J. Barnett, PharmD, MS, Health Services Research Specialist, Iowa City VAMC, Highway 1, Iowa City, IA 52246. Tel: (319) 338-0581, ext. 7659l; Fax: (319) 887-4932;

E-mail: mitchell-barnett@uiowa.edu

Copyright $\odot$ 2006, Academy of Managed Care Pharmacy. All rights reserved.
W hile elderly persons make up only $13 \%$ of the population, they account for 35\% of prescription drug use. ${ }^{1,2}$ Previous research has suggested that the number of elderly on potentially inappropriate medications ranges from $17 \%$ to $29 \%$, based upon expert consensus criteria. . $^{3-7}$ This disproportionately high rate of medication use, compounded with altered pharmacodynamics and pharmacokinetics, places the elderly at increased risk of adverse drug events (ADEs) related to inappropriate medication use. ${ }^{4}$ These ADEs may include cognitive impairment, sedation, depression, constipation, falls, immobility, confusion, and hip fractures. ${ }^{8}$ Inappropriate medication prescribing in the elderly has also been associated with an increased rate of hospitalization. Specifically, it has been estimated that elderly receiving potentially inappropriate medications have a $27 \%$ to $32 \%$ increased risk of hospitalization compared with elderly not receiving these drugs., ${ }^{9} 10$

The Veterans Health Administration, one of the largest integrated health care systems in the United States, includes ambulatory, acute, and long-term care and pharmacy benefits. In recent years, studies have highlighted the high quality of care in the VA compared with the private sector across many domains of quality such as preventive care, disease-specific process of care measures, and clinical outcomes. ${ }^{11-13}$ One measure of quality of medication prescribing is the use of lists of potentially inappropriate medications in the elderly based on evidence and expert consensus. The most frequently used, the Beers criteria derived using a modified Delphi technique, was modified by Zhan to include 33 inappropriate drugs divided into 3 major classifications: "always avoid," "rarely appropriate," and "some indications" (hereafter Zhan criteria). ${ }^{8,14}$

There are limited data comparing prescribing quality, by any metrics, of a large, integrated health care system like the VA with private sector systems. Using a recently published article describing inappropriate medication use in U.S. health maintenance organization (HMO) members, ${ }^{3}$ we directly compare rates of inappropriate drug use in the elderly in VA and private sector HMO populations.

\section{Methods}

Data for private sector patients $(\mathrm{N}=157,517)$ were obtained from the results of a recently published article by Simon et al. ${ }^{3}$ The authors collected data from $10 \mathrm{HMOs}$ in geographically diverse locations across the United States from January 2000 through June 2001. The following areas were included: Worcester, MA; Seattle, WA; Boston, MA; Minneapolis, MN; Detroit, MI; Atlanta, GA; Portland, OR; Denver, CO; Oakland, CA; and Albuquerque, NM. 
Patient demographic data (i.e., age, gender, and geographic region) as well as prescription drug information were obtained from administrative databases. Practices from participating HMOs were randomly selected, and all patients associated with a selected $\mathrm{HMO}$ were included in the study sample. Eligible patients had to be aged 65 years or older in January 2000 and continuously enrolled (no interruptions for periods of $\geq 45$ days) in the HMO for the entire 18-month study period.

VA administrative data were obtained from the Decision Support System (DSS) Outpatient Pharmacy database maintained by the VA Health Economics Resource Center at the VA Medical Center in Palo Alto, CA, and the Outpatient Care File (OPC) databases maintained by the VA Automation Center in Austin, TX. The DSS pharmacy files contain patient-level information on all outpatient prescriptions filled in an outpatient VA pharmacy. The OPC files are part of a set of linked databases that provide patientlevel information on all outpatient encounters from VA facilities and have been used extensively in health services research.

VA administrative files were used to identify outpatients aged 65 years and older from 10 geographical regions $(\mathrm{N}=154,252)$ analogous to the locations used to collect data for the private sector HMO cohort. All VA patients within each location were included in the sample. Eligible patients had to be aged 65 years or older in April 2002 and were assumed to be alive and continuously enrolled during the 18-month period (April 2002 through September 2003) if they received care from the VA during the following year $(\mathrm{N}=123,633)$. A later time frame for VA patients was utilized because VA pharmacy data was not available for the time periods used to collect the HMO data (January 2000 through June 2001).

Inappropriate medication use was identified utilizing the frequently used Zhan criteria, which lists 33 inappropriate drugs as potentially inappropriate regardless of dose, dosing frequency, or duration of use. ${ }^{4}$ The Zhan criteria further divides these individual drugs into 3 major classifications: always avoid, rarely appropriate, and some indications.

Overall comparisons between the VA and the private sector were performed. Comparisons stratifying by gender and age were also conducted, as these stratifications were previously reported by Simon et al. and because we were using a predominantly male VA cohort. To test for differences between cohorts, chi-square tests for proportions were utilized. All analyses were conducted using SAS for Windows, Version 9.1 (SAS Institute; Cary, NC). The Institutional Review Board at University of Iowa Carver College of Medicine and Iowa City VA Medical Center approved the project.

\section{Results}

A total of 123,633 VA patients aged 65 years and older were identified in 10 geographical regions analagous to the ones used by Simon et al. ${ }^{3}$ Table 1 shows the age and gender distibutions for VA and private sector patients. Compared with the private sector, a greater proportion of VA patients were male (97\% vs. 44\%).

\begin{tabular}{l|c|c}
\hline \multicolumn{2}{c|}{ TABLE 1) Baseline Characteristics of Patients } \\
\hline Characteristic & $\begin{array}{r}\text { Veterans Administration } \\
\text { N=123,633 (\%) }\end{array}$ & $\begin{array}{c}\text { Private Sector HMO* } \\
\text { N=157,517 (\%) }\end{array}$ \\
\hline Gender & $120,322(97.3)$ & $68,547(43.5)$ \\
Male & $3,311(2.7)$ & $88,970(56.5)$ \\
Female & $74.7 \pm 5.8$ & NA \\
\hline Mean age \pm SD (years) & $24,666(20.0)$ & $49,095(31.1)$ \\
\hline Age (years) & $34,392(27.8)$ & $42,092(26.7)$ \\
$65-69$ & $34,086(27.6)$ & $33,716(21.4)$ \\
$70-74$ & $23,508(19.0)$ & $19,571(12.4)$ \\
$75-79$ & $6,981(5.7)$ & $13,041(8.3)$ \\
$80-84$ & $>85$ &
\end{tabular}

* Private sector HMO data from Simon et al. ${ }^{3}$

$\mathrm{HMO}=$ health maintenance organization; $\mathrm{NA}=$ not available.

\begin{tabular}{|c|c|c|c|c|c|}
\hline & $\begin{array}{l}\text { rivate Sect } \\
\text { happropria } \\
\text { verall (An } \\
\text { lassificatio } \\
\text { ppropriate }\end{array}$ & $\begin{array}{l}\text { tor HMO P } \\
\text { te Medica } \\
\text { y Categor } \\
\text { n, i.e., Alv } \\
\text { e, and Som }\end{array}$ & $\begin{array}{l}\text { atients } \\
\text { tions (Zr } \\
\text { y), and } \\
\text { vays Avc } \\
\text { ne Indica }\end{array}$ & $\begin{array}{l}\text { Who Rec } \\
\text { han-Crite } \\
\text { by Zhan } \\
\text { sid, Rare } \\
\text { ation }\end{array}$ & $\begin{array}{l}\text { ceived } \\
\text { eria), }\end{array}$ \\
\hline & $\begin{array}{c}\text { VA } \\
(\mathrm{N}=123,633)\end{array}$ & $\begin{array}{c}\mathrm{HMO} \\
(\mathrm{N}=157,517)\end{array}$ & $\begin{array}{c}\text { Absolute } \\
\text { Difference }\end{array}$ & $\begin{array}{c}\text { Relative } \\
\text { Difference }\end{array}$ & $P$ Value \\
\hline verall (any category) & $21.3 \%$ & $28.8 \%$ & $-7.6 \%$ & $-26.2 \%$ & $<0.001$ \\
\hline \multicolumn{6}{|l|}{$\begin{array}{l}\text { han classification } \\
\text { tegory* }\end{array}$} \\
\hline Always avoid & $1.5 \%$ & $5.1 \%$ & $-3.6 \%$ & $-70.4 \%$ & $<0.001$ \\
\hline Rarely appropriate & $7.6 \%$ & $13.4 \%$ & $-5.8 \%$ & $-43.3 \%$ & $<0.001$ \\
\hline Some indications & $14.8 \%$ & $17.1 \%$ & $-2.3 \%$ & $-13.5 \%$ & $<0.001$ \\
\hline
\end{tabular}

$\mathrm{HMO}=$ health maintenance organization; $V A=$ Veterans Administration

Lesser proportions of VA patients were in the youngest (65-69 years) and oldest ( $\geq 85$ years) age categories, $20 \%$ versus $31 \%$ and $6 \%$ versus $8 \%$, respectively.

Table 2 shows the proportion of VA and HMO patients who received inappropriate medications in the always avoid ( $1.5 \%$ vs. $5.1 \%, P<0.001)$, rarely appropriate $(7.6 \%$ vs. $13.4 \%, P<0.001)$, some indications ( $14.8 \%$ vs. $17.1 \%, P<0.001)$, or overall $(21.3 \%$ vs. $28.8 \%, P<0.001)$ classifications for the Zhan criteria. For all categories, absolute and relative rates of use were lower in the VA cohort.

Tables 3 and 4 report the rates of inappropriate medication use for the private sector HMO cohort and VA cohort, respectively, stratified by gender and age, for overall classifications and the 33 individual medications. Overall rates of inappropriate medication use were higher among females than males for both 
Comparison of Rates of Potentially Inappropriate Medication Use According to the Zhan Criteria for VA Versus Private Sector Medicare HMOs

\section{FIGURE 1 Percent Difference in Inappropriate Medication Use by Zhan Class \\ and Individual Medications Between Private Sector HMO and VA Cohorts}

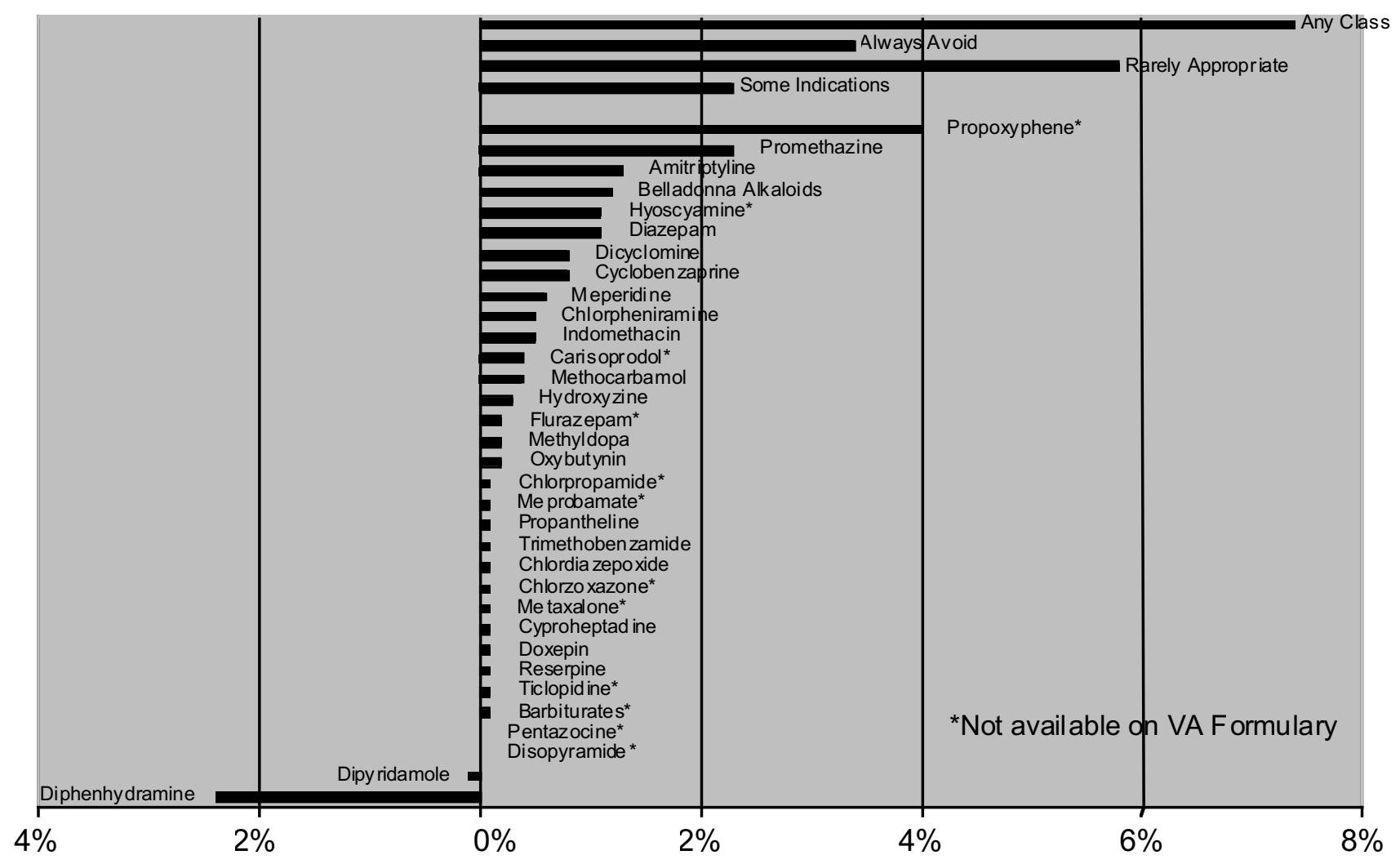

Rate Higher for VA Cohort

Rate Higher for HMO Cohort

the private sector $(32.4 \%$ vs. $24.2 \%, P<0.001)$ and VA $(27.7 \%$ vs. $21.1 \%, P<0.001)$ populations. Further, rates of use for the always avoid classification were higher among females than males in the private sector $(6.1 \%$ vs. $3.8 \%$; $P<0.001)$ as well as the VA cohort ( $2.3 \%$ vs. $1.5 \%, P<0.001)$. Variation of inappropriate medication use among age categories was also observed, varying from $26.8 \%$ to $30.9 \%$ for any use among the private sector HMOs, and $19.1 \%$ to $22.7 \%$ among VA patients.

Figure 1 shows the absolute differences in overall rates between the private sector and VA cohorts for each medication. Among all patients, VA patients had equal or lower rates for 31 of the 33 individual drugs, the exceptions being diphenhydramine and dipyridamole, both of which are in the least severe classification (some indications).

Table 5 lists the differences in rates stratified by gender and age categories. When stratified by gender, female VA patients had lower or equal rates of inappropriate utilization for 28 of the 33 individual drugs, while VA males had lower or equal rates for 27 of the individual drugs, none of which were in the always avoid classification for either males or females. Private sector females had the greatest absolute difference in higher utilization for propoxyphene $(4.9 \%, P<.001))$ and promethazine $(2.3 \%, P<.001)$ relative to VA patients, while VA females had the greatest absolute difference in higher utilization for oxybutynin $(3.3 \%, P<.001)$ and diphenhydramine $(2.8 \%, P<.001)$. Private sector males had the greatest absolute differences in higher utilization for propoxyphene $(2.0 \%)$, indomethacin $(1.6 \%)$, and promethazine (1.6\%) relative to VA patients, while VA males had the greatest absolute differences in higher utilization for diphenhydramine (2.5\%) and oxybutynin (1.1\%) relative to private sector males.

When stratified by age, VA patients had lower or equal rates of inappropriate medication use for 29 to 32 of the 33 individual drugs for the various age categories (65-69, 70-74, 75-79, 80-84, and 85 years and older). VA patients had higher rates of utilization for diphenhydramine in each of the age categories. Other individual drugs for which VA patients had higher utilization in specific 
Comparison of Rates of Potentially Inappropriate Medication Use According to the Zhan Criteria for VA Versus Private Sector Medicare HMOs

TABLE 3 Rates of Use of Potentially Inappropriate Medications by Elderly Private Sector HMO Patients From 10 Geographical Regions, 2000-200 ${ }^{3}$

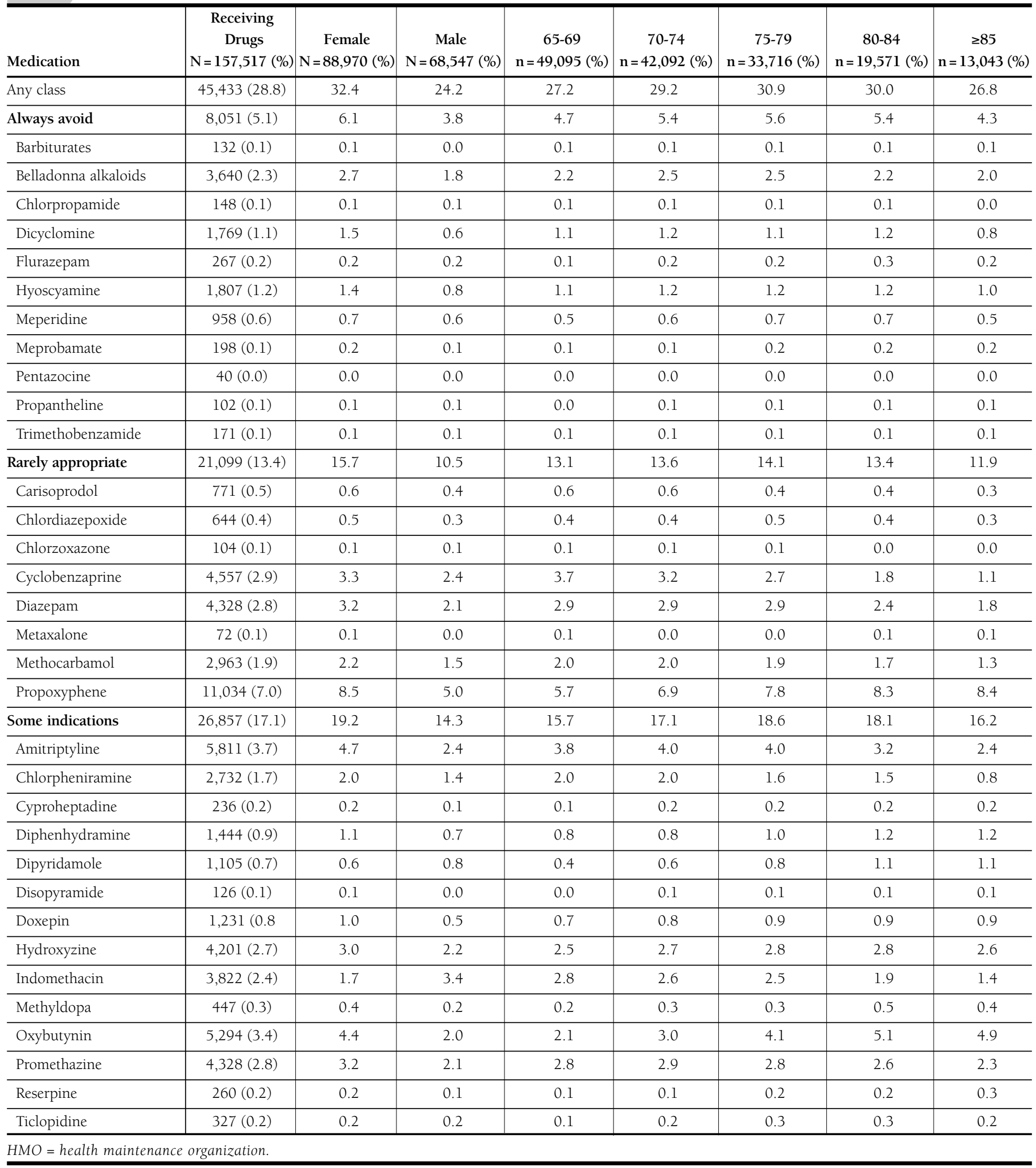


age categories included dipyridamole (65-69 and 75-79 years), oxybutynin (65-69 years), and methocarbamol (65-69 years). For all other drugs and age stratifications, private sector patients had equal or higher rates of inappropriate medication utilization. Propoxyphene had the greatest absolute difference for higher use among private sector patients relative to VA patients in each of the age categories $(2.6 \%, 3.9 \%, 4.9 \%, 4.3 \%$, and $5.5 \%$ for $65-69$, 70-74, 75-79, 80-84, and 85 years and older, respectively). Promethazine represented the second greatest absolute difference in each of the age categories, varying from $1.9 \%$ to $2.4 \%$ among the various age categories. Rates for use within the 3 classifications (always avoid, rarely appropriate, and some indications) were lower for VA patients relative to private sector for each of the age categories.

\section{Discussion}

In the largest comparison to date of inappropriate drug use in VA and private sector elderly patients, we found a consistently lower rate of inappropriate drug use in elderly veterans overall and when stratified by gender and age. The drugs with the highest overall rates of use in the VA sample included diphenhydramine (3.3\%), propoxyphene (3.0\%), amitriptyline (2.4\%), hydroxyzine (2.4\%), and diazepam (1.7\%). The overall rate of $21.3 \%$ is consistent with prior studies ${ }^{3-7,15}$ but remains high.

An important finding is that the difference in rates between the private sector $\mathrm{HMO}$ and VA cohorts in the always avoid (5.1\% vs. $1.5 \%$ ) and rarely appropriate (13.4\% vs. $7.6 \%$ ) classifications were significantly lower in the VA health system. Further, in none of the subpopulation comparisons of the individual agents were VA rates higher than the private sector for any agents in the always avoid classification. The use of the always avoid medications in the elderly can rarely, if ever, be justified. These potentially clinically meaningful differences demonstrate that, through an integrated approach to the delivery of health care, systematic differences in care can be achieved. This cohort study does not prove a causeand-effect relationship. It does, however, demonstrate a meaningful relationship and suggests a higher quality of medication prescribing, as measured by this one metric of medication appropriateness, in the elderly in the VA health system. It also suggests that up to $21 \%$ of VA patients are still taking medications they should avoid.

There are several factors that may explain the lower rate of inappropriate drug use in the elderly in the VA health system. First, the primary reason for this observed difference is that the VA could have a lot to do with the limited national drug formulary that restricts access to many of these medications. In fact, 12 of the 33 medications in the Zhan-criteria list are not available through the VA unless a specific formulary exemption is requested by the provider and granted by the clinical pharmacist and/or chief of staff. Specifically, 6 of the 11 always avoid, 4 of the 8 rarely appropriate, and 2 of the 14 some indications medications are not available on the VA formulary. Another reason for the apparent lower rate of use of Zhan-criteria drugs is the use of an integrated computerized patient record system (CPRS) that includes automatic order checks for high-risk drugs in the elderly and drugdrug interactions. Finally, VA interventions and initiatives to improve quality of care, such as the use of clinical pharmacists and comprehensive medication reconciliation, may also decrease use of potentially inappropriate medications. Use of similar interventions by the private sector $\mathrm{HMO}$ was not discussed by Simon et al.; hence, comparison on these factors is not possible.

Some of the overall difference in rates can be explained by a larger percentage of women in the private sector cohort $(56.5 \%$ vs. $2.7 \%$ ). However, the magnitude of the difference between the VA and private sector stratified by gender is similar. The higher rate of inappropriate drug use in women has been previously reported by Goulding in a national sample with an odds ratio of 1.96. This difference has been explained by higher use of central nervous system and pain medications in women, ${ }^{16,17}$ and is supported by our findings.

\section{Limitations}

There are several limitations that should be considered in interpreting our results. As noted above, the drug formulary status of the 33 Zhan-criteria drugs was not known for the Medicare HMO patients. Second, we did not have access to the administrative claims in the private sector data. Therefore, direct statistical comparisons were not possible for all potential subgroup analyses, such as geographic variation and mean number of total (Zhan and non-Zhan) medications received during the study time period.

Third, the VA pharmacy data warehouse only captures medications dispensed by the VA health system. At the time the pharmacy data were collected, non-VA medications were not systematically entered into the VA pharmacy database. This includes over-the-counter (OTC) medications that patients purchase on their own as well as prescription medications purchased at non-VA pharmacies. ${ }^{18}$ The VA data may underestimate the actual use of these medications if patients receive them from non-VA providers, but they do capture OTC medications when dispensed by VA pharmacies. While a recent small survey found that a majority (78\%) of VA patients received their medications exclusively from the VA, the study found that $18 \%$ received medications from the VA and their private sector HMO. ${ }^{19}$ Therefore, it is quite likely the private sector cohort included a substantial number of VA patients, while the VA cohort included a substantial number of HMO patients. The net effect on our findings is unknown.

Another limitation is the absence of information about the indications for use of medications that may be considered appropriate in some circumstances. ${ }^{20}$ However, a prior study based on a nationwide elderly VA cohort found that even when adjusting for diagnoses, dose, and duration, the absolute rate of inappropriate drug use was reduced $10 \%$, from $33 \%$ to $23 \% .{ }^{21}$ More specifically, the study found adjusted rates of rarely appropriate and some 
Comparison of Rates of Potentially Inappropriate Medication Use According to the Zhan Criteria for VA Versus Private Sector Medicare HMOs

\section{TABLE 4 Rates of Use of Potentially Inappropriate Medications by Elderly} VA Patients From 10 Geographical Regions, 2002-2003

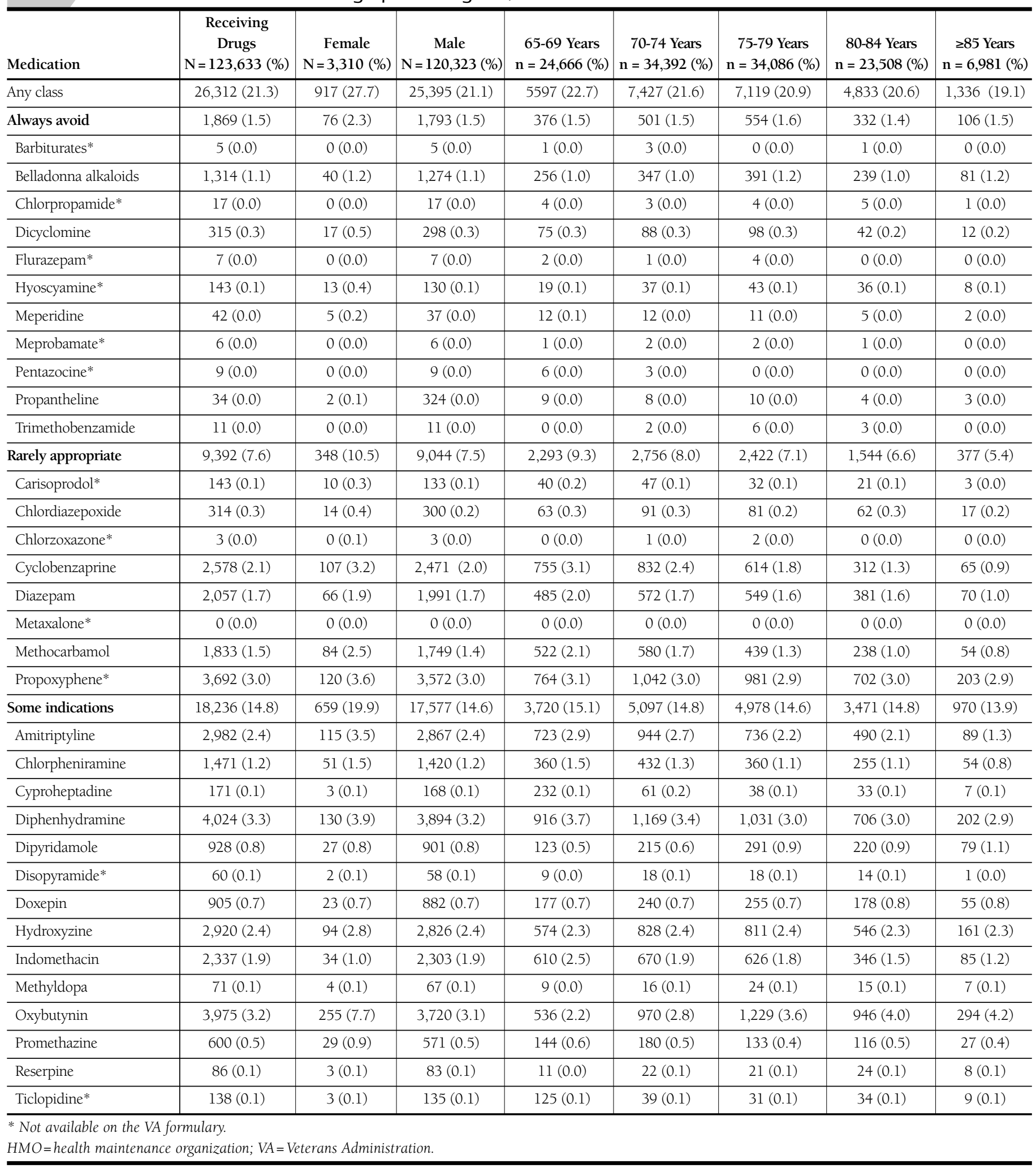


Comparison of Rates of Potentially Inappropriate Medication Use According to the Zhan Criteria for VA Versus Private Sector Medicare HMOs

TABLE 5 Difference in Rates of Potentially Inappropriate Medications Between Private Sector HMO and VA Patients Limited to Medications Available on the VA Formulary

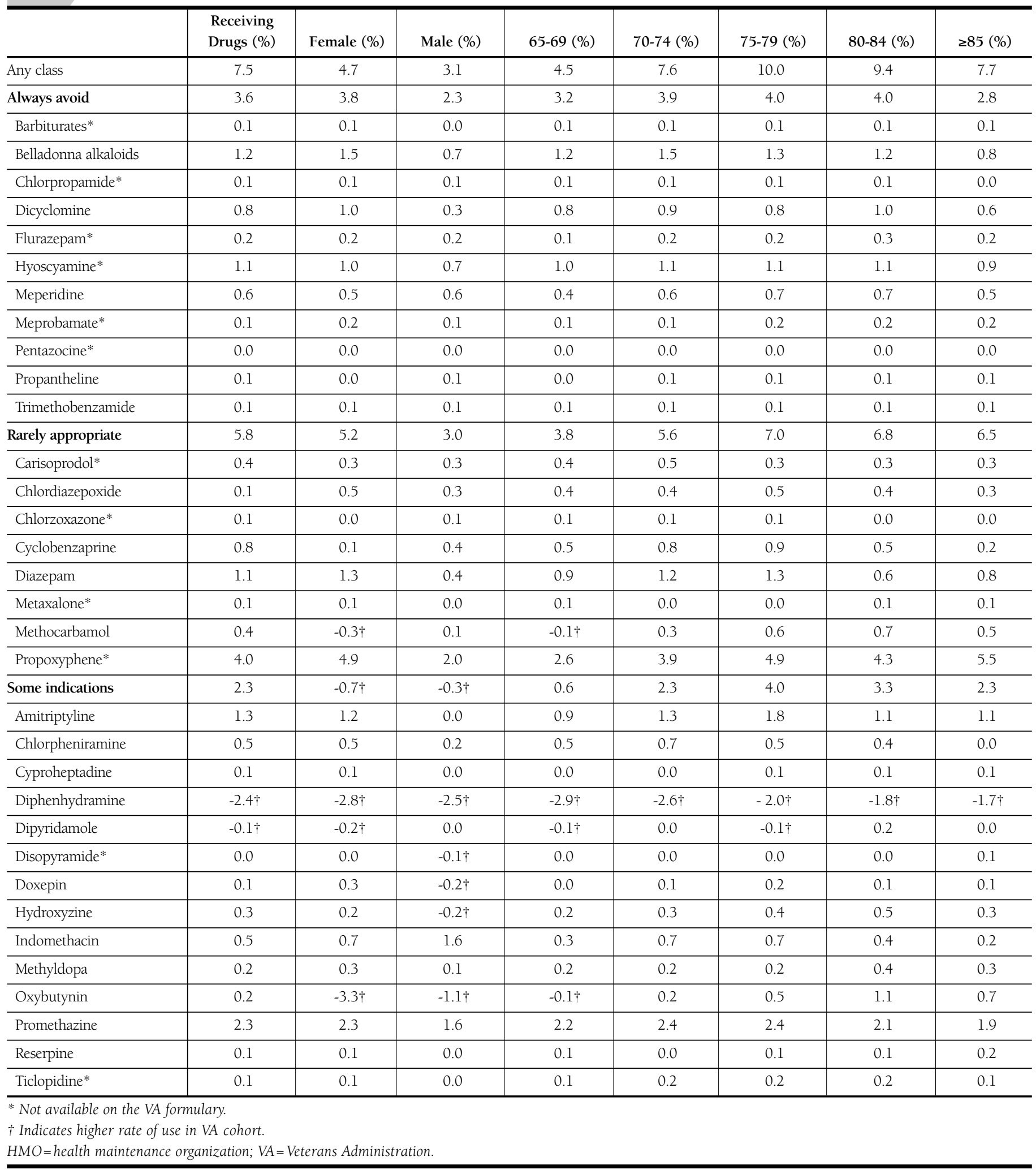




\section{Comparison of Rates of Potentially Inappropriate Medication Use According to the Zhan Criteria for VA Versus Private Sector Medicare HMOs}

indications of $8.0 \%$, and $13.3 \%$, respectively; leading the authors to reject the premise that most potentially inappropriate medications may be proper, based on indication and duration. Similar to our findings, the authors found highest rates associated with propoxyphene, amitriptyline, and benzodiazepines. The time period for comparison between the 2 cohorts was not exactly the same. However, it is unlikely that significant changes in rates of use occurred during this 1-year period. Finally, Simon et al. reported results stratified by Chronic Disease Score (CDS) quintiles, finding that sicker patients were more likely to be taking inappropriate medications. The VA administrative data file did not have the necessary elements to calculate the CDS for direct comparison. However, previous work has shown that VA patients have more comorbid conditions, ${ }^{22}$ leading to a higher CDS than the private sector, which may bias our results in favor of the private sector.

Although our findings do add to the list of studies examining the use of potentially inappropriate drugs prescribed to patients, ${ }^{23}$ it goes beyond these studies to compare different systems of health care. The VA integrated health care system has been cited as a model for high-quality care in the United States, ${ }^{24}$ and the presence of a paperless medical record, physician order entry, automatic alerts, drug checks, a restricted national formulary, and a culture of quality all may work in synergy to improve prescribing and drug use in elderly veterans. Unfortunately, the rates of use of these medications are still relatively high, and initiatives should focus on eliminating many of these drugs from the VA formulary, further restricting their use, and, most importantly, recommending safer alternatives.

\section{Conclusion}

When cohorts of VA health system and private sector Medicare HMO patients were compared, the VA patients were less likely to receive potentially inappropriate medications as defined by the Zhan criteria. These findings add to the body of literature that suggests that while the VA health system may deliver a higher quality of measurable outpatient care than private sector delivery systems, as much as $21 \%$ of VA health system patients may be receiving potentially inappropriate medications. These results also suggest the potential effectiveness of a restricted formulary in reducing utilization of potentially inappropriate medications. Yet to be measured is the contribution of computerized order entry, integrated electronic medical records, and centralized formularies in less prescribing of potentially inappropriate medications.

\section{ACKNOWLEDGMENTS}

We would like to thank Elise Acosta, program associate, The Center for Research in the Implementation of Innovative Strategies in Practice (CRIISP), Iowa City VA Medical Center, Iowa City, Iowa, for her assistance with preparation of the manuscript.

\section{DISCLOSURES}

No outside funding supported this study research. The work reported here was supported by the Department of Veterans Affairs, Veterans Health Administration, Health Services Research and Development Service (SAF 98-1521). Author Peter J. Kaboli is supported by a Research Career Development Award from the Health Services Research and Development Service, Department of Veterans Affairs (RCD 03-033-1). The views expressed in this article are those of the authors and do not necessarily represent the views of the Department of Veterans Affairs. The authors disclose no potential bias or conflict of interest relating to this article.

Author Mitchell J. Barnett served as principal author of the study. Study concept and design were contributed by Barnett and author Paul J. Perry, with input from Kaboli and author Jodi D. Langstaff. Data collection was the work of Barnett, with input from the coauthors; data interpretation was primarily the work of Kaboli, with input from the coauthors. Writing of the manuscript was the work of all the authors; its revision was the work of Barnett and Kaboli, with input from Perry and Langstaff.

\section{REFERENCES}

1. Hanlon JT, Fillenbaum GG, Kuchibhatla M, et al. Impact of inappropriate drug use on mortality and functional status in representative community dwelling elders. Med Care. 2002;40(2):166-76.

2. Curtis LH, Ostbye T, Sendersky V, et al. Inappropriate prescribing for elderly Americans in a large outpatient population. [see comment]. Arch Intern Med. 2004;164(15):1621-25.

3. Simon SR, Chan KA, Soumerai SB, et al. Potentially inappropriate medication use by elderly persons in U.S. health maintenance organizations, 2000-2001.

J Amer Geriatr Soc. 2005;53(2):227-32.

4. Zhan C, Sangl J, Bierman AS, et al. Potentially inappropriate medication use in the community-dwelling elderly: findings from the 1996 Medical Expenditure Panel Survey. JAMA. 2001;286(22):2823-29.

5. Stuart B, Briesacher B. Medication decisions—right and wrong. Med Care Res Rev. 2002;59(2):123-45.

6. Hanlon JT, Fillenbaum GG, Schmader KE, Kuchibhatla M, Horner RD. Inappropriate drug use among community-dwelling elderly. Pharmacotherapy. 2000;20(5):575-82.

7. Hanlon JT, Schmader KE, Boult C, et al. Use of inappropriate prescription drugs by older people. J Am Geriatr Soc. 2002;50(1):26-34.

8. Fick DM, Cooper JW, Wade WE, Waller JL, Maclean JR, Beers MH. Updating the Beers criteria for potentially inappropriate medication use in older adults: results of a US consensus panel of experts. Arch Intern Med. 2003;163(22): 2716-24.

9. Willcox SM, Himmelstein DU, Woolhandler S. Inappropriate drug prescribing for the community-dwelling elderly. JAMA. 1994;272(4):292-96.

10. Klarin I, Wimo A, Fastbom J. The association of inappropriate drug use with hospitalisation and mortality: a population-based study of the very old. Drugs Aging. 2005;22(1):69-82.

11. Jha AK, Perlin JB, Kizer KW, Dudley RA. Effect of the transformation of the Veterans Affairs Health Care System on the quality of care. N Engl J Med. 2003; 348(22):2218-27.

12. Asch SM, McGlynn EA, Hogan MM, et al. Comparison of quality of care for patients in the Veterans Health Administration and patients in a national sample. Ann Intern Med. 2004;141(12):938-45.

13. Kaboli PJ, Barnett MJ, Fuehrer SM, Rosenthal GE. Length of stay as a source of bias in comparing performance in VA and private sector facilities: lessons learned from a regional evaluation of intensive care outcomes. Med Care. 2001; 39(9):1014-24.

14. Beers MH. Explicit criteria for determining potentially inappropriate medication use by the elderly. An update. Arch Intern Med. 1997;157(14):1531-36.

15. Aparasu RR, Mort JR, Brandt H. Psychotropic prescription use by communitydwelling elderly in the United States. J Am Geriatr Soc. 2003;51(5):671-77. 
16. Goulding MR. Inappropriate medication prescribing for elderly ambulatory care patients. Arch Intern Med. 2004;164(3):305-12.

17. Roe CM, McNamara AM, Motheral BR. Gender- and age-related prescription drug use patterns. Ann Pharmacother. 2002;36:30-39

18. Kaboli PJ, McClimon BJ, Hoth AB, Barnett MJ. Assessing the accuracy of computerized medication histories. Am J Manag Care. 2004;10(11 pt 2):872-77.

19. Hester EJ, Cook DJ, Robbins LJ. The VA and Medicare HMOs-complementary or redundant? N Engl J Med. 2005;353(12):1302-03.

20. Crownover BK, Unwin BK. Implementation of the Beers criteria: sticks and stones or throw me a bone. J Manag Care Pharm. 2005;11(5):416-17.
21. Pugh MJ, Fincke BG, Bierman AS, et al. Potentially inappropriate prescribing in elderly veterans: are we using the wrong drug, wrong dose, or wrong duration? J Am Geriat Soc. 2005;53(8):1282-89.

22. Rosenthal GE, Kaboli PJ, Barnett MJ. Differences in length of stay in Veterans Health Administration and other United States hospitals: is the gap closing? Med Care. 2003;41(8):882-94.

23. Avorn J. Improving drug use in elderly patients: getting to the next level. JAMA. 2001;286(22):2866-68

24. Perlin JB, Kolodner RM, Roswell RH. The Veterans Health Administration: quality, value, accountability, and information as transforming strategies for patient-centered care. Am J Manag Care. 2004;10(11 pt 2):828-36. 